
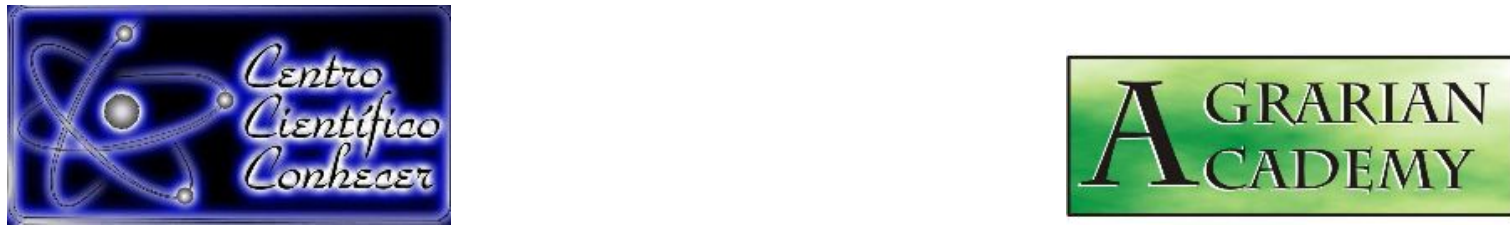

\title{
AVALIAÇÃO DE EXTRATOS ETANÓLICOS DA BORRA DE CAFÉ COMO INDICADORES DE pH
}

\footnotetext{
Aluísio Marques da Fonseca ${ }^{1}$, Carla Patrícia Costa Oliveira², Regilany Paulo Colares $^{3}$, Juan Carlos Alvarado Alcócer ${ }^{4}$, Olienaide Ribeiro de Oliveira Pinto ${ }^{5}$

${ }^{1}$ Professor Doutor da Universidade da Integração Internacional da Lusofonia Afro-Brasileira (UNILAB), Redenção-CE, Brasil.

${ }^{2}$ Graduação em Engenharia de Energias, Universidade da Integração Internacional da Lusofonia Afro-Brasileira (UNILAB), Redenção-CE, Brasil.

${ }^{3}$ Professora Doutora da Universidade da Integração Internacional da Lusofonia AfroBrasileira (UNILAB), Redenção-CE, Brasil.

${ }^{4}$ Professor Doutor da Universidade da Integração Internacional da Lusofonia Afro-Brasileira (UNILAB), Redenção-CE, Brasil.

${ }^{5}$ Doutora, Bolsista do Programa Nacional de Pós-Doutorados (PNPD)/CAPES, Universidade da Integração Internacional da Lusofonia Afro-Brasileira (UNILAB), Redenção-CE, Brasil. Email: agron.olienaide@gmail.com.
}

\section{Recebido em: 02/06/2019 - Aprovado em: 15/06/2019 - Publicado em: 22/07/2019} DOI: 10.18677/Agrarian_Academy_2019a7

\section{RESUMO}

O objetivo do trabalho foi estudar uma aplicação do extrato etanólico da borra de café como indicadores de $\mathrm{pH}$. O extrato utilizado para a análise da característica de indicação de $\mathrm{pH}$ foi obtido com etanol, realizado em diferentes concentrações. Realizou-se em seguida as soluções tampões de diferentes concentrações em pH variando de 1 a 12 e misturados aos extratos etanólicos preparados anteriormente, na proporção de $1 \mathrm{~mL}$ de solução tampão para $1 \mathrm{~mL}$ dos extratos nas concentrações de $0,125 \mathrm{~g} \mathrm{~mL}^{-1}, 0,0625 \mathrm{~g} \mathrm{~mL}^{-1}, 0,031 \mathrm{~g} \mathrm{~mL}^{-1}$ e $0,015 \mathrm{~g} \mathrm{~mL}^{-1}$. As colorações obtidas nos diferentes valores de $\mathrm{pH}$ foram registradas por imagens digitais. Posteriormente, foi realizada uma leitura espectrofotométrica dos extratos preparados com o intuito de obter um comprimento de onda que possibilitasse a leitura da absorbância de todas as misturas, com diferentes colorações obtidas a partir dos extratos misturados às soluções tampão. Com o comprimento de onda adequado, realizou-se a leitura de todas as absorbâncias e os resultados obtidos passaram a compor o conjunto de dados acumulados sobre essas misturas em função do $\mathrm{pH}$, sendo eles, coloração, concentração e absorbância. Como resultado, percebeu-se que os extratos da borra de café podem ser utilizados como indicador de $\mathrm{pH}$. Extratos de menores concentrações apresentaram maior eficiência neste processo mostrando cores mais facilmente diferenciáveis, mesmo para valores de $\mathrm{pH}$ próximos e principalmente para meios básicos. Portanto, os extratos podem se apresentar como facilitadores no aprendizado de Química quando se mostram como alternativas acessíveis e de baixo custo aos indicadores comercialmente disponíveis.

PALAVRAS-CHAVE: antocianinas, estudo da borra de café, indicador natural de $\mathrm{pH}$. 


\title{
EVALUATION OF ETHANOLIC EXTRACTS OF THE COFFEE BLADE AS INDICATORS OF $\mathrm{pH}$
}

\begin{abstract}
The objective of this work was to study the application of ethanolic extract of coffee grounds as $\mathrm{pH}$ indicators. The extract used to analyze the $\mathrm{pH}$ indicating characteristic was obtained with ethanol, performed at different concentrations. Buffer solutions of different concentrations of $\mathrm{pH}$ varying from 1 to 12 and mixed with the ethanolic extracts prepared previously were used in the ratio of $1 \mathrm{ml}$ of buffer solution to $1 \mathrm{ml}$ of the extracts at the concentrations of $0.125 \mathrm{~g} \mathrm{~mL}^{-1} ; 0.0625 \mathrm{~g} \mathrm{~mL}^{-1} ; 0.031 \mathrm{~g} \mathrm{~mL}^{-1}$ and $0.015 \mathrm{~g} \mathrm{~mL}^{-1}$. The colorations obtained at the different $\mathrm{pH}$ values were recorded by digital images. Subsequently, a spectrophotometric reading of the prepared extracts was carried out with the aim of obtaining a wavelength that allowed reading the absorbance of all the mixtures, with different color obtained from the extracts mixed to the buffer solutions. At the appropriate wavelength, all absorbances were read and the results obtained were composed of the set of data accumulated on these mixtures as a function of $\mathrm{pH}$, being they, staining, concentration and absorbance. As a result, it was noticed that extracts of coffee grounds can be used as a $\mathrm{pH}$ indicator. Extracts of lower concentrations showed higher efficiency in this process, showing more easily differentiated colors, even for near and mainly $\mathrm{pH}$ values for basic media. Therefore, the extracts can be presented as facilitators in the learning of Chemistry when they are shown as accessible and low-cost alternatives to commercially available indicators.
\end{abstract}

KEYWORDS: Natural pH indicator, Study of coffee grounds, Anthocyanins.

\section{INTRODUÇÃO}

A estimativa da safra brasileira de café (Coffea arabica) em 2018 foi de 59,9 milhões de sacas e corresponde a um terço da produção mundial (CONAB, 2018). Anualmente são geradas 225 milhões de toneladas de resíduos líquidos e 9,9 milhões de toneladas de resíduos sólidos em nível mundial, sendo assim, a borra de café é um resíduo sólido com a presença de grande quantidade de material orgânico além de conter compostos tóxicos como a cafeína, taninos e polifenóis (HERMOSA, 2014).

A borra de café (BC) é gerada tanto na produção industrial como nos lares, restaurantes, cafeterias, entre outros, e contêm elevadas concentrações de matéria orgânica, açúcares, compostos orgânicos e inorgânicos (DURÁN et al., 2017). A BC é um resíduo com tamanho de partícula muito fino e alta umidade, carga orgânica e acidez, gerada durante a produção de café instantâneo. Um dos principais problemas encontrados pela indústria de café é à disposição desses resíduos, que muitas vezes é descarga no esgoto ou nos aterros sanitários, incineração, alimentação animal, utilização como enchimento e adsorvente em material termofixo, adubo para as plantas e utilização como combustível (GARCÍA; BIANCHI, 2015).

Os indicadores químicos são substâncias capazes de mudar de cor dependendo das características físico-químicas da solução na qual estão contidos. Estas substâncias podem ser encontradas na natureza em diversas plantas, folhas e frutos e começaram a ser observadas e estudadas desde o século XVII por Robert Boyle (TERCl; ROSSI, 2002). As antocianinas, pigmentos da classe dos flavonóides, são um grupo de substâncias naturais que apresentam esta característica, podendo ser utilizadas como indicadores naturais de pH (UCHÔA et al., 2016), estes 
compostos estão presentes no café e lhe conferem cor avermelhada ou amarelada (SÁGIO, 2009).

A utilização de extratos naturais das plantas fontes de antocianina para a indicação de $\mathrm{pH}$ de substâncias apresenta uma grande vantagem frente aos indicadores comercialmente utilizados pelo seu baixo custo e disponibilidade. Muitas espécies de plantas já são atualmente estudadas com este propósito (TERCl; ROSSI, 2002).

Além disso, o próprio processo de extração destes pigmentos até o estudo da aplicação deles como indicadores de $\mathrm{pH}$ pode ser analisado como uma forma mais didática e prática de aprendizado de diversos processos e conceitos químicos, evidenciando uma outra grande vantagem da utilização destes indicadores naturais de pH. De acordo com Silva et al. (2018) o uso de extratos de plantas como indicadores naturais de $\mathrm{pH}$ é uma ferramenta importante no processo de ensino e aprendizagem que visam o desempenho ambiental dos processos, impactando em menores custos, maior segurança, menor risco à saúde e ao meio ambiente.

Desta forma, este trabalho teve como objetivo o estudo da utilização de extratos etanólicos da B.C. como indicadores de $\mathrm{pH}$, na busca por uma alternativa para o reaproveitamento deste recurso, que normalmente é desperdiçado, e para o desenvolvimento de um método de análise de $\mathrm{pH}$ que possa apresentar custo mais baixo, maior disponibilidade e que ainda tenha a possibilidade de se mostrar como um processo simples e que contribua para o aprendizado de Química quando aplicado de forma íntegra à estudantes desta área.

\section{METERIAL E MÉTODOS \\ Procedimento de avaliação de extratos etanólicos da B.C}

O trabalho foi realizado no laboratório de Biotecnologia e Ciências Naturais (LABioCN), Química Orgânica e Química Inorgânica da Universidade da Integração Internacional da Lusofonia Afro-Brasileira (UNILAB), Campus das Auroras, no município de Redenção, Ceará, nas coordenadas: latitude 4ํ 13' 33' Sul e longitude 38 43' 50" Oeste (IPECE, 2017).

O procedimento para a avaliação de extratos etanólicos da B.C. como indicadores de $\mathrm{pH}$ se iniciou com a preparação de soluções etanólicas de B.C. em diferentes concentrações para se verificar quais foram as mais eficientes na indicação de $\mathrm{pH}$ ao serem adicionadas a diferentes soluções tampão, nos valores de $\mathrm{pH}$ que variaram de 1 a 12.

As concentrações dos extratos etanólicos da B.C. variaram de $0,125 \mathrm{~g} \mathrm{ml}^{-1}$; $0,0625 \mathrm{~g} \mathrm{ml}^{-1} ; 0,031 \mathrm{~g} \mathrm{ml}^{-1}$ e $0,015 \mathrm{~g} \mathrm{ml}^{-1}$ e foram nomeadas como E1, E2, E3 e E4, respectivamente. Estas soluções foram preparadas adicionando-se a massa necessária de B.C. ao volume determinado de álcool etílico e deixando-se o conteúdo em repouso por 20 minutos. As misturas foram então filtradas utilizando papel filtro.

\section{Avaliação de extratos etanólicos da B.C. como indicador de pH}

Soluções tampão incolores e também de 12 valores de $\mathrm{pH}$ diferentes, foram preparadas para a realização dos testes, no qual $1 \mathrm{ml}$ de extrato de B.C. foram colocados em 12 diferentes tubos de ensaio e a coloração de cada tubo foi registrada por fotografia após a adição de um $\mathrm{mL}$ de solução tampão dos 12 valores de $\mathrm{pH}$ em cada tubo de ensaio.

Em seguida, realizou-se uma leitura espectrofotométrica dos extratos preparados, obtendo-se uma curva de absorbância versus comprimento de onda. 
Esse procedimento teve a finalidade em determinar o comprimento de onda para a leitura das absorbâncias de todas as misturas de diferentes colorações obtidas a partir dos extratos misturados às soluções tampão, utilizando um comprimento de onda adequado.

\section{RESULTADOS E DISCUSSÃO}

Para os extratos etanólicos E1, E2, E3 e E4, foram observadas diferenças de coloração de acordo com o pH para todas as concentrações, sendo observados maior diferença de cor entre valores de $\mathrm{pH}$ próximos e tons mais distintos de castanho para as concentrações mais baixas, como pode ser analisado na Figura 1, onde o extrato E1 apresentou os melhores resultados.

Com este resultado, pode-se perceber que o café possui um componente que apresenta cor diferente dependendo do $\mathrm{pH}$ do meio em que se encontra. $\mathrm{O}$ extrato passou a apresentar uma coloração castanha mais escura que a inicial em meios básicos, enquanto nos meios ácidos a coloração ficou bem mais clara que a inicial. Nota-se ainda, que ocorreu uma maior diferença de coloração nos meios básicos, onde houve uma variação maior entre os tons de castanho, facilitando a identificação de valores de $\mathrm{pH}$ próximos e mostrando a maior eficiência deste extrato como indicador de valores de $\mathrm{pH}$ maiores que 7 (básicos).

Estudos com vegetais utilizando extrato etanólico como indicador alternativo de $\mathrm{pH}$ foram realizados por Silva et al. (2018) que avaliaram, repolho roxo, beterraba, cebola roxa, açafrão-da-terra, feijão-preto e berinjela, que contaram com a participação de estudantes dos cursos de Licenciatura em Química e de Licenciatura em Ciências Biológicas.

No extrato de açafrão-da-terra, por exemplo, Silva et al. (2018) observaram variação das colorações obtidas nas amostras que foram testadas a partir do extrato de rizomas de açafrão que possuem curcumina. Sueth-Santiago et al. (2015) abordam que a curcumina apresenta equilíbrio ceto-enólico entre o $\mathrm{pH} 3$ e o pH 7, tem baixa solubilidade em água, mas é solúvel em soluções aquosas básicas, além de, apresenta várias propriedades biológicas relevantes, dentre elas antioxidante, anti-inflamatória e antitumoral. Situação semelhante ocorreu no estudo com a borra de café (B.C), sendo uma maior diferença de coloração nos meios básicos.

Silva et al. (2018) revelam ainda, que os extratos de açafrão-da terra aquoso e etanólico podem ser utilizados por até 22 dias após a extração, sem comprometer a detecção qualitativa do $\mathrm{pH}$ das amostras testadas, apresentando coloração amarela em vinagre, $\mathrm{HCl} 0,1 \mathrm{~mol} \mathrm{~L}^{-1}$, refrigerante, água e etanol; laranja em $\mathrm{NaOH}$ $0,1 \mathrm{~mol} \mathrm{~L}^{-1}$; e amarelo claro em água sanitária.

No estudo com borra de café (B.C) como indicador de pH pode se evitar que esse resíduo seja desperdiçado, pois segundo García e Bianchi (2015) muitas vezes esse produto é descarregado em esgoto, aterros sanitários, usado na alimentação de animal, como adubo para as plantas e como biomassa para combustível.

Dessa forma, estudantes da área de Química, por exemplo, podem ter a possibilidade de conhecer como um processo simples pode contribuir para o ensino e na aprendizagem. Isso mostrou o quanto é importante o uso de produtos naturais como indicador de pH obtido de vegetais, e de acordo com Silva et al. (2018) impacta em menores custos, maior segurança, menor risco à saúde e ainda preservar o meio ambiente. 

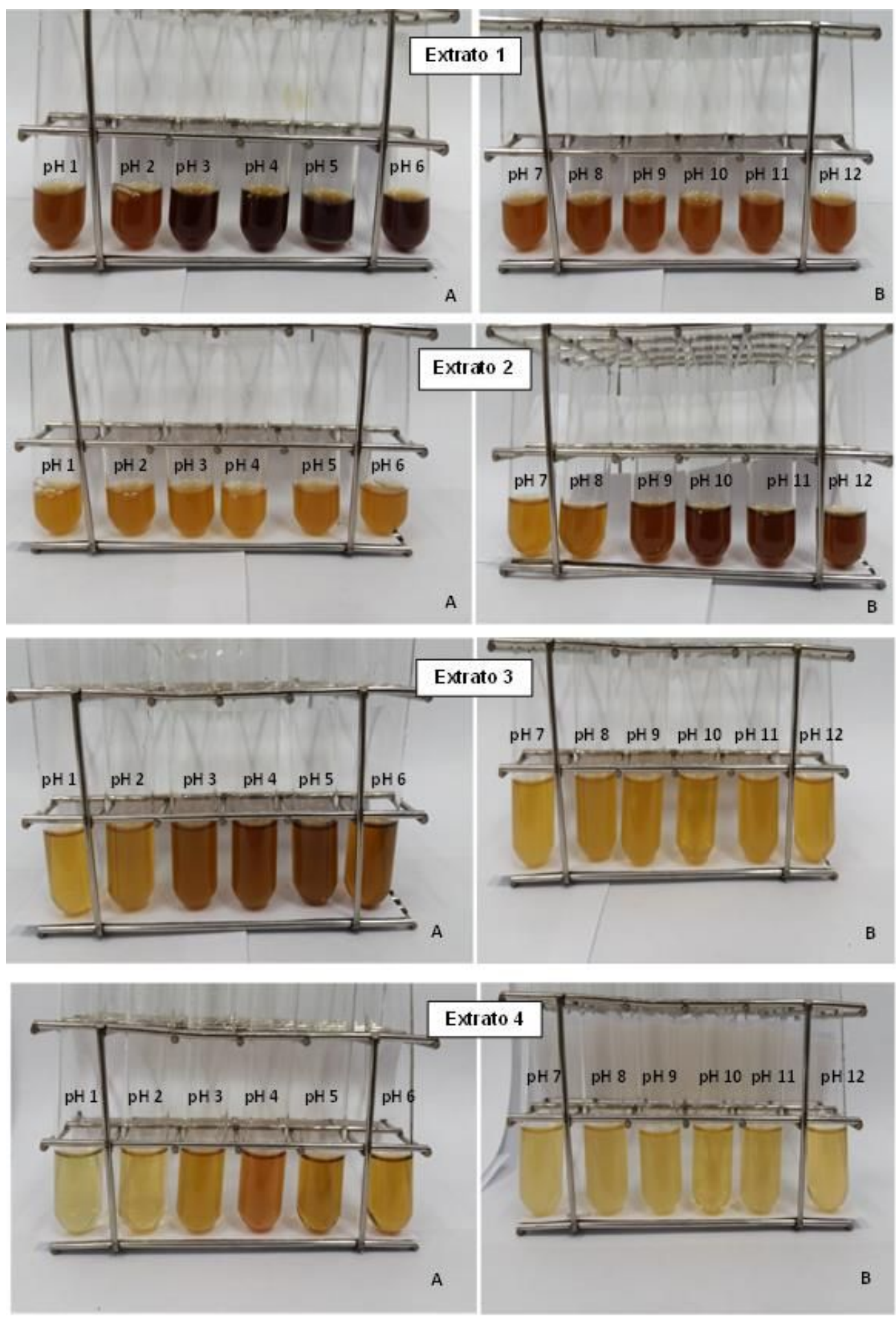

FIGURA 1. Extrato 1, Extrato 2, Extrato 3 e Extrato 4 após a adição das soluções tampão de valores de $\mathrm{pH}$ variando $1 \mathrm{a} 12$, respectivamente, da esquerda para a direita (A e B).

Terci e Rossi (2002) mencionam que indicadores naturais de $\mathrm{pH}$ utilizando papel ou solução das frutas dos extratos de amora, jabuticaba, jambolão e uva permitem medidas de faixas de $\mathrm{pH}$ mais estreitas quando comparados com os papéis de filtro, podendo ser usado com considerável confiabilidade para medidas de AGRARIAN ACADEMY, Centro Científico Conhecer - Goiânia, v.6, n.11; p. 77 
pH em meio aquoso, independente da coloração da solução que está sendo testada. Afirmam ainda, que podem ser empregadas didaticamente para favorecer a articulação entre teoria e prática no ensino superior e médio, valorizando a pesquisa individual e coletiva.

Pietro et al. (2017) desenvolveram filmes de amido contendo extrato de feijãopreto e de repolho roxo como membranas sensíveis à variação de $\mathrm{pH}$, e observaram que pode ser utilizado como embalagens inteligentes, possuindo em comum as antocianinas glicosiladas petuninida e cianidina e a antocianina não glicosilada pelargonidina.

No trabalho realizado por Uchôa et al. (2016) afirmaram que as tonalidades de cores apresentadas pelos extratos da alamanda-amarela e do louro variegado se mostraram mais expressivos em termos de diferenciação de uma cor com outra em função da ordem crescente de acidez e basicidade, ou seja, de fraco a forte quando equiparado com as cores de extratos de beterraba e repolho roxo, que são de cores claras em sua maioria na faixa de $\mathrm{pH}$ na maior parte dos casos estudados.

O comprimento de onda para a leitura da absorbância dos extratos foi determinado através da determinação da curva de absorbância versus comprimento de onda para uma amostra do extrato E1-E4, como mostrados na Figura 2.

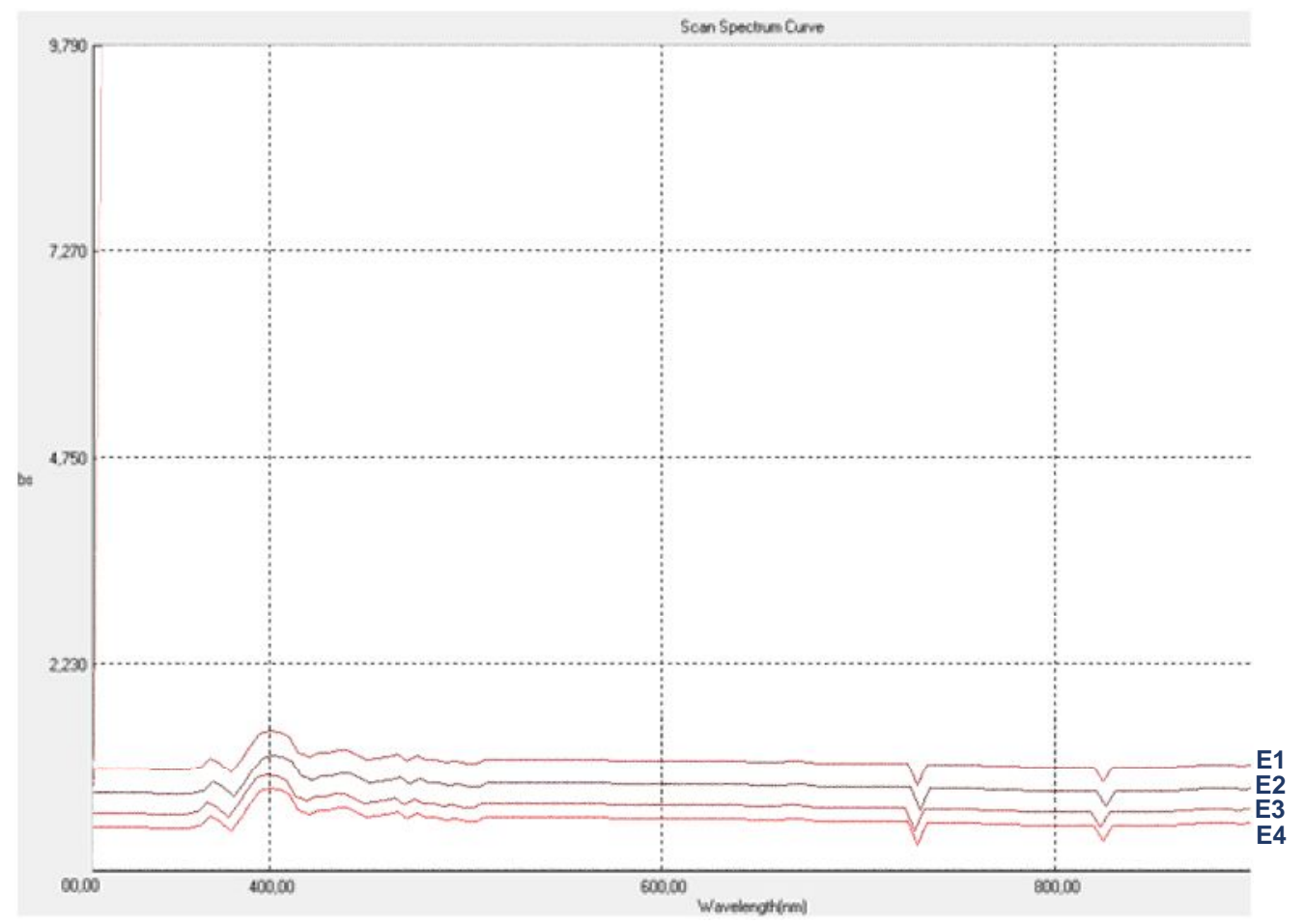

FIGURA 2. Absorbância versus comprimento de onda para os extratos E1-E4.

A partir da análise do gráfico da Figura 2, pode-se perceber um pico de absorbância em $400 \mathrm{~nm}$ de comprimento de onda, logo, a medida da absorbância dos extratos foi realizada para este comprimento de onda e os resultados são mostrados na Figura 3 e Tabela 1. 


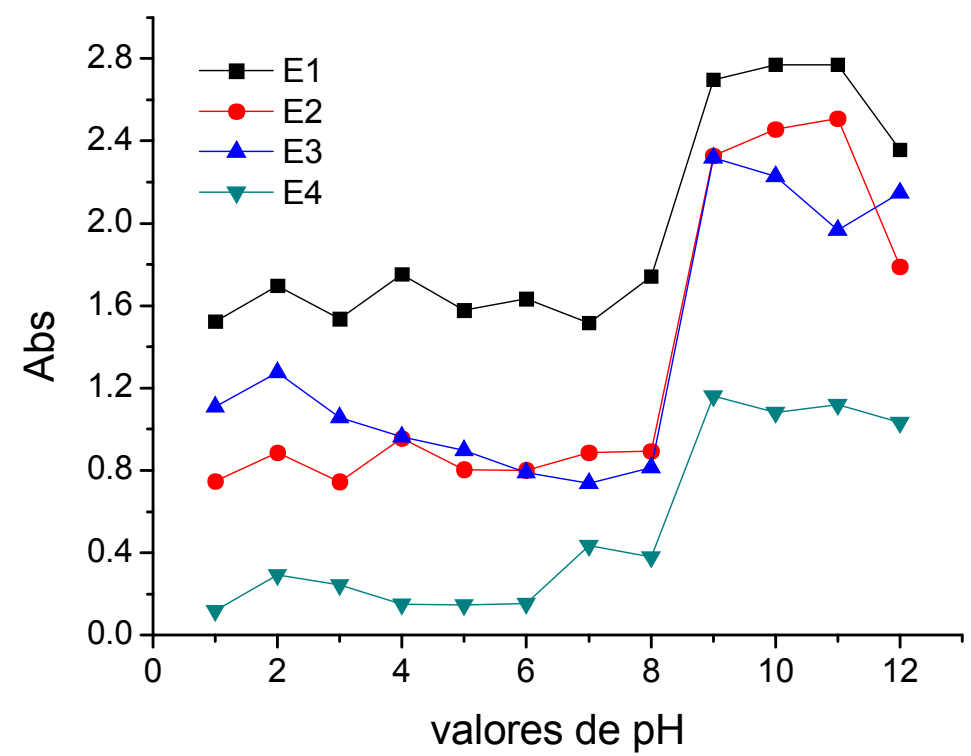

FIGURA 3. Absorbância versus valores de pH para os extratos E1-E4.

TABELA 1. Absorbância em função do pH para cada extrato.

\begin{tabular}{ccccc}
\hline \multicolumn{5}{c}{ Absorbância a 400 nanômetros } \\
\hline $\mathrm{pH}$ & Extrato 1 & Extrato 2 & Extrato 3 & Extrato 4 \\
\hline 1 & 1,523 & 0,747 & 1,108 & 0,119 \\
2 & 1,697 & 0,886 & 1,276 & 0,291 \\
3 & 1,535 & 0,745 & 1,056 & 0,243 \\
4 & 1,752 & 0,955 & 0,963 & 0,149 \\
5 & 1,578 & 0,804 & 0,896 & 0,146 \\
6 & 1,633 & 0,801 & 0,788 & 0,153 \\
7 & 1,516 & 0,886 & 0,738 & 0,434 \\
8 & 1,742 & 0,893 & 0,815 & 0,378 \\
9 & 2,698 & 2,327 & 2,319 & 1,161 \\
10 & 2,770 & 2,456 & 2,229 & 1,081 \\
11 & 2,770 & 2,509 & 1,967 & 1,119 \\
12 & 2,357 & 1,790 & 2,149 & 1,032 \\
\hline
\end{tabular}

Através dos valores obtidos, pode-se constatar que a absorbância foi maior para os extratos de maior concentração, E1 e E2 de concentrações $0,125 \mathrm{~g} \mathrm{ml}^{-1} \mathrm{e}$ $0,0625 \mathrm{~g} \mathrm{ml}^{-1}$, respectivamente, que também foram os extratos de colorações mais escuras após a adição das soluções tampão, e menor para o extrato $E 4$, de colorações mais claras, indicando uma proporcionalidade entre a concentração do extrato, a coloração após a adição das soluções tampão e a absorbância das amostras.

Pinheiro e Lima (1999) avaliaram o comportamento do extrato aquoso da casca de barbatimão, tanto em meio ácido quanto em meio básico, e verificaram a modificação de coloração associada à forma dos espectros, ou seja, dos máximos 
de absorção, tiveram como resposta que em meio ácido, predominou a coloração amarelada com pH abaixo de 5,0, com ponto de máximo em 445,6 nm. Já, no meio básico o pH ficou acima de 8,0, com uma coloração laranja rosada, com intensificação da banda em 500,3 nm, sendo a mudança de coloração atribuída à variação estrutural de misturas de corantes presentes no extrato.

Guimarães et al. (2012) revelam que muitas espécies de plantas (jaboticaba, jambolão, petúnia, pata de vaca, flor de picão, repolho roxo, etc.) possuem propriedades indicadoras em potencial de $\mathrm{pH}$, representando, portanto, uma alternativa de uso a serem aplicadas como indicador em titulações ácido-base. Segundo os autores para amostras que são investigadas deve-se observar uma nítida e rápida mudança de coloração em função da variação do $\mathrm{pH}$, característica fundamental para um indicador.

\section{CONCLUSÕES}

A partir do estudo, percebe-se que extratos da borra de café (B.C) podem ser utilizados como indicador de $\mathrm{pH}$. Extratos de menores concentrações apresentaram maior eficiência neste processo mostrando cores mais facilmente diferenciáveis, mesmo para valores de $\mathrm{pH}$ próximos e principalmente para meios básicos. Assim, estes extratos podem se apresentar como facilitadores no aprendizado de Química quando se mostram como alternativas acessíveis e de baixo custo aos indicadores comercialmente disponíveis.

\section{REFERÊNCIAS}

CONAB - Companhia Nacional de Abastecimento. Café, Safra/2018. Terceiro levantamento, Brasília, p.1-76, 2018. Disponível em: <https://www.conab.gov.br/>.

DURÁN, C. A., TSUKUI, A., SANTOS, F., MARTINEZ, S. T., BIZZO, H. R., \& REZENDE, C. M. Café: Aspectos Gerais e seu Aproveitamento para além da Bebida. Revista Virtual Química, v.9, n.1, p.107-134, 2017.

GARCÍA, L. R. P.; BIANCHI, V. L. D. Capacidade antioxidante em resíduos da indústria cafeeira. Brazilian Journal Food Technology, v.18, n.4, p. 307-313, 2015. Disponível em: <http://www.scielo.br/pdf/bjtt/v18n4/1981-6723-bjft-18-4-307.pdf>. DOI: http://dx.doi.org/10.1590/1981-6723.5015.

GUIMARÃES, W.; ALVES, M. I. R.; ANTONIOSI FILHO, N. R. Antocianinas em extratos vegetais: aplicação em titulação ácido-base e identificação via cromatografia líquida/espectrometria de massas. Química Nova, v.35, n.8, p.1673-1679, 2012. Disponível em: <http://www.scielo.br/scielo.php?script=sci_abstract\&pid=S010040422012000800030\&lng=pt\&tIng=pt>. DOI: http://dx.doi.org/10.1590/S010040422012000800030 .

HERMOSA, V. A. B. Aproveitamento dos resíduos do processamento semi-seco do café para a produção de compostos de valor agregado. Dissertação (Mestrado em Microbiologia agrícola) - Universidade Federal de Lavras, Lavras, 2014.

Disponível

em: <http://www.sbicafe.ufv.br/bitstream/handle/123456789/6858/Dissertacao_Veronica \%20Alejandra\%20Bonilla\%20Hermosa. pdf? sequence=1\&isAllowed $=y>$. 
IPECE - Instituto de Pesquisa e Estratégia Econômica do Ceará. Perfil municipal de Redenção. $18 p$. 2017.2 Disponível em: $<$ https://www.ipece.ce.gov.br/wpcontent/uploads/sites/45/2018/09/Redencao_2017.p df>.

PINHEIRO, M. H. T.; LIMA, W. N. Estudo da utilização do extrato aquoso de barbatimão (Stryphnodendron barbatimão, M.) no ensino de química. Eclética Química, $\quad$ v.24, $1999 . \quad$ Disponível em: $<$ http://www.scielo.br/scielo.php?script=sci_arttext\&pid=S0100-

46701999000100001\&lng=pt\&tlng=pt>. _ DOI:http://dx.doi.org/10.1590/S010046701999000100001.

PRIETTO, L.; MIRAPALHETE, T. C.; PINTO, V. Z.; HOFFMANN, J. F.; VANIER, N. L.; LIM, L.T., GUERRA DIAS, A. R.; ZAVAREZE, E. R. pH-sensitive films containing anthocyanins extracted from black bean seed coat and red cabbage, LWT - Food Science and Technology, v.80, p. 492-500, 2017. Disponível em: <https://www.sciencedirect.com/science/article/pii/S0023643817301512> DOI: https://doi.org/10.1016/j.Iwt.2017.03.006.

SÁGIO, S. A. Características fisiológicas e bioquímicas de frutos de duas cultivares de café de ciclos de maturação precoce e tardio. Dissertação (Mestrado) - Universidade Federal de Lavras, Minas Gerais. 2009. Disponível em: <http://www.sbicafe.ufv.br/bitstream/handle/123456789/6466/Dissertacao_Solange\% 20Aparecida\%20Sagio.pdf?sequence $=1$ \&isAllowed $=\mathrm{y}>$.

SILVA, D. B.; GONÇALVES, M. M.; KREVE, Y. D.; NICOLINI, K. P.; NICOLINI, J. Coleção de propostas utilizando produtos naturais para a introdução ao tema ácidobase (parte II): extração e armazenamento. Educación Química, v.29, n.2, p.3-16 2018.

Disponível

em: <http://www.revistas.unam.mx/index.php/req/article/view/63702>.

DOI: 10.22201/fq.18708404e.2018.1.63702.

SUETH-SANTIAGO, V., MENDES-SILVA, G. P.; DECOTÉ-RICARDO, D.; LIMA, M. E. F. Curcumina, o pó dourado do açafrão-da-terra: introspecções sobre química e atividades biológicas, Química Nova, n.38, n.4, p.538-552, 2015. Disponível em: $<$ http://quimicanova.sbq.org.br/imagebank/pdf/v38n4a14.pdf>.

http://quimicanova.sbq.org.br/imagebank/pdf/v38n4a14.pdf.

TERCI, D. B. L.; ROSSI, A. V. Indicador natural de pH: usando papel ou solução? Química Nova, v.25, n.4, p. 684-688, 2002. Disponível em: <http://www.scielo.br/scielo.php?script=sci_arttext\&pid=S010040422002000400026> . DOI: http://dx.doi.org/10.1590/S0100-40422002000400026.

UCHÔA, V. T.; CARVALHO FILHO, R. S. M.; LIMA, A. M. M.; ASSIS, J. B. Utilização de plantas ornamentais como novos indicadores naturais ácido-base no ensino de química, Holos, v.2, n.32, p.1-14, 2016. Disponível em: <http://www2.ifrn.edu.br/ojs/index.php/HOLOS/article/view/3869>.

DOI: 10.15628/holos.2016.3869. 